\title{
Impact of Current Ripple on Electric Vehicle Charging Equipment
}

\author{
Zhang Hechuan \\ Technical Skills Training Center of State Grid Jibei Electric Power Company Limited, Baoding, \\ Hebei 071051, China. \\ zhanghc1023@126.com
}

Keywords: electric vehicle (EV), charging equipment, ripple, current ripple coefficient, efficiency Abstract. In the experimental study of electric vehicle (EV) charging equipment performance testing, we found that when the EV charging equipment charged the power battery in a constant current mode, some charging devices output current contained a lot of current ripples. Thus, the index of voltage ripple coefficient had not been able to evaluate the charging performance of charging equipment accurately and comprehensively. In reaction to the phenomenon, this paper quantified the impact of the current ripples on the conversion efficiency, the security and the reliability of the charging equipment through theoretical analysis, simulation and experimental verification, and the results showed that the current ripples have important influence on chargers. Based on the research results, this paper suggested that bringing the technical index of current ripple coefficient into the technical specification of EV charging equipment.

\section{Introduction}

Electric vehicles had low noise, low emissions and high efficiency advantages. Popularizing and developing EV can effectively reduce the industry's dependence on oil and other non-renewable resources. It is a significant measure to solve energy security and environmental pollution problems [1-4]. The demand of charging equipments which supply energy for EV will increase rapidly with the development of EV industry. The output electrical performances of EV charging devices will not only affect the battery's charging efficiency and safety, but also the safe operation and service life of the charger itself. The paper [5] analyzed the output voltage ripple calculate method of Boost converter operating in continuous conduction mode (CSM) and a discontinuous conduction mode (DCM), The literature [6] studied the influences of output voltage ripple current on Boost Converter stability, The literature [7-9] researched the generation, measurement methods and restraining measures of voltage ripple.

However, in actual experiments we found that: when charging in constant current mode to the power battery, some chargers contained a large amount of current ripples. This phenomenon showed that using only the voltage ripple coefficient and its limits can't evaluate the charging performance of charging equipment accurately and comprehensively. On this basis, the paper quantified the effect of the current ripples on the conversion efficiency, the security and the reliability of the charging equipment through theoretical analysis, simulation and experimental verification.

\section{Concept and evaluation indicators of ripple}

Voltage ripple and voltage ripple coefficient. Voltage ripple referred to the AC component voltage superposed on the DC stabilizing. The ratio of voltage ripple and DC voltage was called voltage ripple factor. Voltage ripple factor including peak and RMS ripple factor [10], respectively is calculated as formula (1) and (2).

$$
\begin{aligned}
& X_{R M S}=\frac{U_{R M S}}{U_{D C}} \times 100 \% \\
& X_{P P}=\frac{U_{P P}}{2 U_{D C}} \times 100 \%
\end{aligned}
$$


Here, $X_{R M S}$ : RMS ripple factor; $X_{P}$ : peak ripple factor; $U_{R M S}$ : the RMS of AC component voltage; $U_{P P}$ : the difference between the peak and valley value of the output voltage; $U_{D C}$ : the average value of DC output voltage.

Propose current ripple coefficient. Fig. 1 were the waveforms of one EV on-board charger charged to the battery in constant current mode when current values were set to $2 \mathrm{~A}, 4 \mathrm{~A}, 5 \mathrm{~A}, 6 \mathrm{~A}$. The output currents of charger were equal to the set values in average, but contained a lot of current ripples. Current cyclically waved between $-2 \mathrm{~A} \sim 12 \mathrm{~A}$, its frequency was about $1 \mathrm{kHz}$.

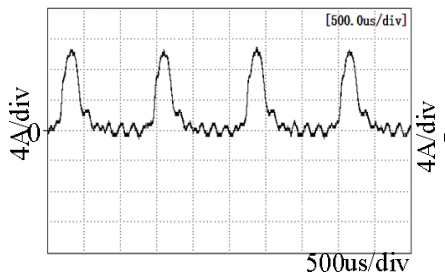

current set value:2[A]

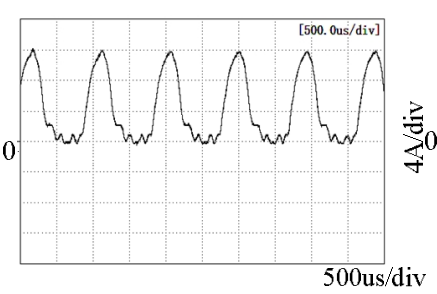

current set value:4[A]

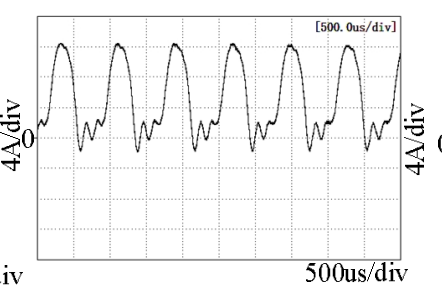

current set value:5[A]

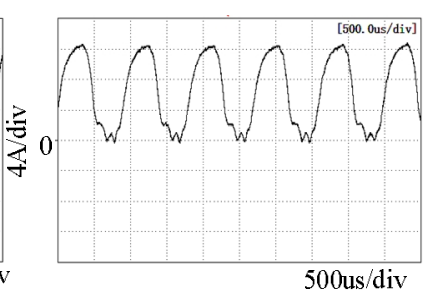

current set value:6[A]

Fig.1 Current ripples of different current setting values

So we proposed the current ripple and current ripple coefficient as one index of charger electrical performance. Current ripple referred to the AC component current superposed on the DC stabilizing. The ratio of current ripple and DC current was called current ripple factor. Current ripple factor including peak and RMS ripple factor [10], respectively is calculated as equation (3) and (4)

$$
\begin{gathered}
X_{R M S}=\frac{I_{R M S}}{I_{D C}} \times 100 \% \\
X_{P P}=\frac{I_{P P}}{2 I_{D C}} \times 100 \%
\end{gathered}
$$

Here, $I_{R M S}$ : the RMS of AC component current; $I_{P P}$ : the difference between the peak and valley value of the output current; $I_{D C}$ : the average value of DC output current.

\section{Influence of current ripple on the charging device}

Simulation of influence on the charger internal device. In order to study the diversifications of currents through the internal elements like filter inductor, filter capacitor, IGBT, rectifier diodes when the output current contained a large number of current ripples. This paper researched the effect of large current ripple on the internal components through simulation with PSCAD. Built simulation charger model as Fig.2, the switching frequency of control circuit was selected $25 \mathrm{kHz}$, the charger worked in constant current charging mode, the battery load was substituted by a $340 \mathrm{~V}$ constant voltage source and $0.692 \Omega$ small resistor in series. Fig. 3 was the PI control circuit of simulation.

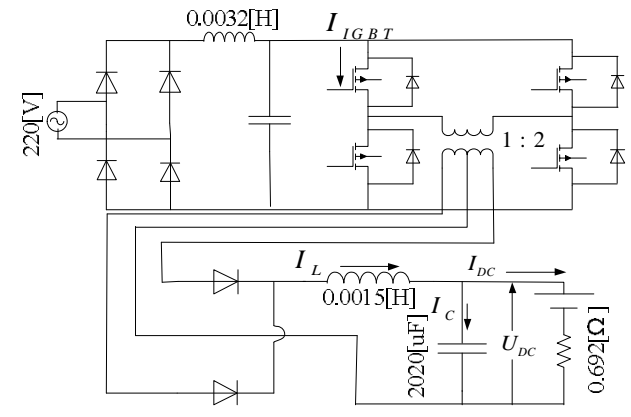

Fig.2 Simulation circuit of charger

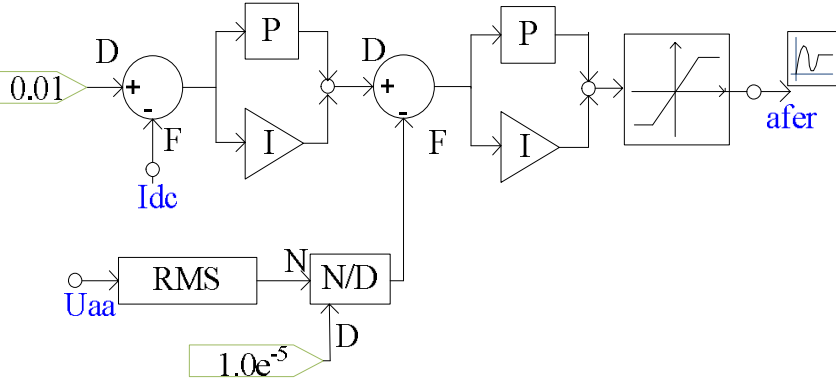

Fig.3 PI control circuit of charger simulation

Adjusting the parameters of the PI controller made the charging machine worked respectively in large current ripple and output small current ripple mode. The average values of output current in two states both were 10A. Output current waveforms as shown in Figure 4 and the currents flowed through 
the output filter capacitor, the output filter inductor, IGBT and rectifier diode respectively as shown in Figures 5 to 8 .

When the charger output current contained large ripples the current fluctuation range of inside components were multiplied. The current and conduction losses flowed through the output filter inductor, output filter capacitor, the output rectifier diodes, IGBT inverter and other internal components in two different states as shown in Tab.1. The power loss of filter inductor and filter capacitor were calculated as formula $I^{2} R$, IGBT and rectifier diode output on-state power loss was calculated as the formula $P=\left(\int_{0}^{T}\right.$ uidt $) / T$.
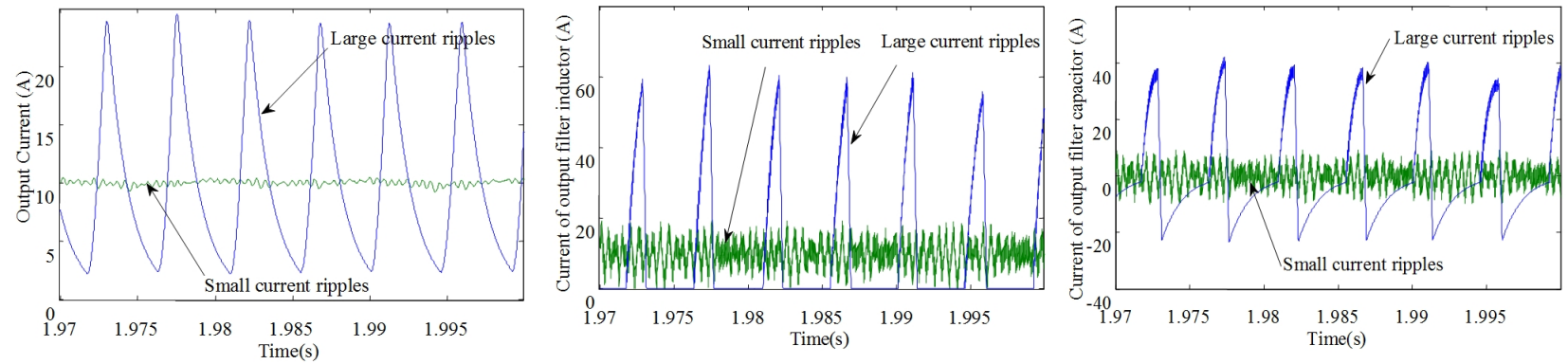

Fig.4 Output current of charger Fig.5 Current of output filter inductance Fig.6 Current of output filter capacitance

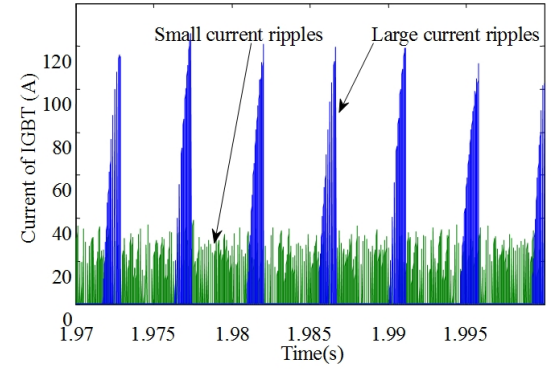

Fig.7 Current of IGBT

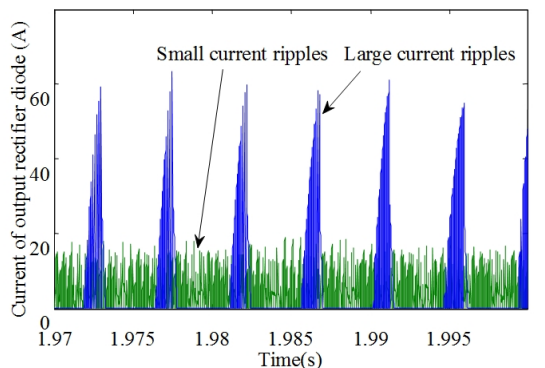

Fig.8 Current of output rectifier diode

Tab.1 Current values through the charger inside devices and power losses

\begin{tabular}{ccccccc}
\hline $\begin{array}{c}\text { Charger } \\
\text { and device }\end{array}$ & $\begin{array}{c}\text { Ripple } \\
\text { current } \\
\text { situation }\end{array}$ & $\begin{array}{c}\text { Average } \\
\text { current(A) }\end{array}$ & $\begin{array}{c}\text { RMS } \\
\text { Current(A) }\end{array}$ & $\begin{array}{c}\text { Range of } \\
\text { current(A) }\end{array}$ & $\begin{array}{c}\text { Current } \\
\text { amplitude } \\
\text { ratio }\end{array}$ & $\begin{array}{c}\text { Conduction } \\
\text { loss ratio }\end{array}$ \\
\hline charger & $\begin{array}{c}\text { large } \\
\text { small }\end{array}$ & 10 & 12 & $2 \sim 25$ & 2.38 & 1.44 \\
Filter & large & 9.9 & 10 & $9.2 \sim 10.5$ & 1 & 1 \\
inductor & small & 10.1 & 10.7 & $0 \sim 67.2$ & 3.31 & 3.85 \\
Filter & large & 0 & 17 & $-24 \sim 45.2$ & 4.35 & 23.6 \\
capacitor & small & 0 & 3.5 & $-10.2 \sim 10.4$ & 1 & 1 \\
IGBT & large & 7.4 & 27 & $0 \sim 134.3$ & 3.31 & 1.5 \\
Rectifier & small & 7.4 & 13.2 & $0 \sim 40.6$ & 1 & 1 \\
diode & large & 5 & 14.3 & $0 \sim 67.2$ & 3.31 & 1.33 \\
\hline
\end{tabular}

As can be seen from Tab.1, the average values in two different working conditions flowed through the respective devices were substantially identical, but the RMS value and current fluctuation range increased in different degree. The ripple coefficient calculated by the equation (3) and (4) output current ripple RMS ripple factor was $20 \%$, the peak ripple factor was $115 \%$. When the output current contained large ripple, the power loss on each device increased exponentially, and the loss of energy were dissipated as heat. It had a greater impact on the temperature of the devices so that made the devices working environment deteriorated. The devices would bear a greater electrical stresses if the peak current increased. Therefore, the choice of IGBT and rectifier diodes and other devices need to 
consider a greater margin, which would increase the manufacturing cost, volume and weight of charger.

Test verification on efficiency of charger. We tested the current ripple factor indicator of one EV charger through charger test system, which consisted of power supply, electronic load and measuring instruments as shown in Fig.9. Measuring instruments were a high-precision power analyzer and an oscilloscope. When the DC load was selected constant resistance mode the current ripple coefficient was relatively small and stable; if the load was power battery or constant voltage mode of electronic load, current ripple coefficient was relatively high, charging current waveform shown in Fig.1. According to the formula (3) and (4), RMS ripple factor up to $80 \%$, the peak ripple factor up to $100 \%$. The following tests verify the impact of the current ripple on efficiency of the charging device.

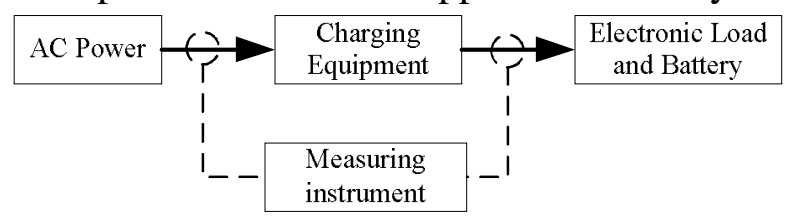

Fig.9 Structure of the Test System

Test scheme. Setting the charger worked in constant current mode, DC load was electronic load in constant voltage mode and constant resistance mode; charging device input voltage was set to $220 \mathrm{~V}$, frequency was set to $50 \mathrm{~Hz}$; charger output voltage test points: $240 \mathrm{~V}, 290 \mathrm{~V}, 340 \mathrm{~V}, 390 \mathrm{~V}$; output current test point: $2 \mathrm{~A}, 4 \mathrm{~A}, 6 \mathrm{~A}, 7.5 \mathrm{~A}$. The measured efficiency of the charging device as shown in Tab. 2 and Tab.3, the difference values of the charging device efficiency in both cases as shown in Tab.4.

Tab.2 the relationship between efficiency and charger output parameters large currents ripple factor

\begin{tabular}{ccccc}
\hline \multirow{2}{*}{$I_{\mathrm{d}}(\mathrm{A})$} & \multicolumn{4}{c}{$\eta / \%$} \\
\cline { 2 - 5 } & $U d=250 \mathrm{~V}$ & $U d=290 \mathrm{~V}$ & $U d=340 \mathrm{~V}$ & $U d=390 \mathrm{~V}$ \\
\hline 2 & 89.09739 & 90.70202 & 92.20129 & 93.62118 \\
4 & 90.97068 & 92.24152 & 93.31637 & 94.15156 \\
6 & 91.59551 & 92.65669 & 93.31174 & 94.04828 \\
7.5 & 91.89958 & 92.60417 & 93.29648 & 93.83262 \\
\hline
\end{tabular}

Tab.3 the relationship between efficiency and charger output parameters small currents ripple factor

\begin{tabular}{ccccc}
\hline \multirow{2}{*}{$I_{\mathrm{d}}(\mathrm{A})$} & \multicolumn{4}{c}{$\eta / \%$} \\
\cline { 2 - 5 } & $U d=250 \mathrm{~V}$ & $U d=290 \mathrm{~V}$ & $U d=340 \mathrm{~V}$ & $U d=390 \mathrm{~V}$ \\
\hline 2 & 92.01465 & 92.66728 & 93.12425 & 93.35516 \\
4 & 93.74245 & 94.08748 & 94.40974 & 94.59944 \\
6 & 93.58885 & 93.93175 & 94.17944 & 94.28365 \\
7.5 & 93.67699 & 93.91492 & 94.0632 & 94.10801 \\
\hline
\end{tabular}

Tab.4 the difference of efficiency between large currents ripple factor and small currents ripple factor

\begin{tabular}{ccccc}
\hline \multirow{2}{*}{$I_{\mathrm{d}}(\mathrm{A})$} & \multicolumn{4}{c}{$\Delta \eta / \%$} \\
\cline { 2 - 5 } & $U d=250 \mathrm{~V}$ & $U d=290 \mathrm{~V}$ & $U d=340 \mathrm{~V}$ & $U d=390 \mathrm{~V}$ \\
\hline 2 & 2.917254 & 1.965256 & 0.922967 & -0.26602 \\
4 & 2.771762 & 1.845964 & 1.093367 & 0.447878 \\
6 & 1.993342 & 1.275064 & 0.867701 & 0.235374 \\
7.5 & 1.777411 & 1.310754 & 0.766723 & 0.275393 \\
\hline
\end{tabular}

Analysis of test results. Tab.4 showed that the charger had higher efficiency worked in small current ripple than large current ripple. The efficiency difference was between $0.2 \%$ and $3 \%$. With the increase of the charger output power the efficiency difference decreased. At light load current ripple effect on the efficiency of the charger was about $2.9 \%$, at full load the impact on charger efficiency was relatively small approximately $0.27 \%$. Thus, the current ripple had a certain influence on the efficiency of the charging device. 


\section{Conclusions}

This article explored the phenomenon of current ripple of EV charger and studied the impact of current ripple on the charging equipment, the following conclusions:

(1) We found in the electrical performance experiment of EV charging equipment that some charger's output current consisted of larger number of ripples when charged to the battery in constant current mode.

(2) When the output current contained large number of ripples power loss on each device increased exponentially, thereby increased the loss of charging device itself, reduced charger's efficiency. At the same time it had a greater impact on the temperature rise of the charging equipment. The devices would bear a greater electrical stresses if the peak current increased. The results of the test suggested that larger current ripples have some influence on the charging device efficiency.

(3) Based on the test result, this paper proposed to add current ripple coefficient in the technical specifications of EV charging equipment.

\section{References}

[1] The state council of the People's Republic of China. Energy saving and new energy vehicles industry development planning(2012 - 2020) [EB/OL].2012-7-9 (in Chinese).

[2] Science and technology department of the People's Republic of China. The electric car "twelfth five-year" development of science and technology special planning[EB/OL]. 2012-3-27(in Chinese).

[3] Lutsey Nicholas, Sperling Daniel. Regulatory adaptation: Accommodating electric vehicles in a petroleum world [J]. Energy Policy, 2012. 45: 308-316

[4] SUN Peng-chun. The current situation and development trend of the electric vehicle [J]. Scientific Chinese, 2006-8: 44-47(in Chinese).

[5] Liu Shulin, Liu Jian, Yang Yinling, Zhao Xinyi. Energy Transmission Modes and Output Ripple Voltage of Boost Converters [J]. Proceedings of the CSEE, 006, 26(5): 119-124(in Chinese).

[6] Yang Yu, Ma Xikui. Effects of Output Voltage Ripple on the Stability of Current-mode Boost Converters [J]. Proceedings of the CSEE, 2007, 27(28): 102-106(in Chinese).

[7] Cheng Hui, Ren Yongfeng, Wang Qiang. Measurement and suppression of power supply ripple [J]. Chinese Journal of Power Sources, 2012, 36(12): 1899-1921(in Chinese).

[8] Fang Yujie, Su Binghua, Hang Lingxia. Study on Ripple Rejection for Switching [J] . Power Supply, 2012, 35(10) : 136-138(in Chinese) .

[9] Yao Xiaoping. Power Supply Line the Creation of Ripple、 Measure and Repress [J]. The World of Power Supply, 2009-11: 40-43(in Chinese).

[10]Market Supervision Administration of Shenzhen Municipality. SZDB/Z 29-2010. The electric vehicle charging system specification[S]. Shenzhen, 2010(in Chinese). 